\title{
A Case of Ipilimumab Induced Hypophysitis
}

\author{
Eric Shiffrin, MD \\ Thomas Jefferson University, eric.shiffrin@jefferson.edu \\ Melinda Ukrainski, MD \\ Thomas Jefferson University, melinda.ukrainski@jefferson.edu
}

Follow this and additional works at: https://jdc.jefferson.edu/tmf

Part of the Medicine and Health Sciences Commons

Let us know how access to this document benefits you

\section{Recommended Citation}

Shiffrin, MD, Eric and Ukrainski, MD, Melinda (2015) "A Case of Ipilimumab Induced Hypophysitis," The Medicine Forum: Vol. 16 , Article 4.

DOI: https://doi.org/10.29046/TMF.016.1.003

Available at: https://jdc.jefferson.edu/tmf/vol16/iss1/4

This Article is brought to you for free and open access by the Jefferson Digital Commons. The Jefferson Digital Commons is a service of Thomas Jefferson University's Center for Teaching and Learning (CTL). The Commons is a showcase for Jefferson books and journals, peer-reviewed scholarly publications, unique historical collections from the University archives, and teaching tools. The Jefferson Digital Commons allows researchers and interested readers anywhere in the world to learn about and keep up to date with Jefferson scholarship. This article has been accepted for inclusion in The Medicine Forum by an authorized administrator of the Jefferson Digital Commons. For more information, please contact: JeffersonDigitalCommons@jefferson.edu. 


\title{
A Case of Ipilimumab Induced Hypophysitis
}

\author{
Eric Shiffrin, MD and Melinda Ukrainski, MD
}

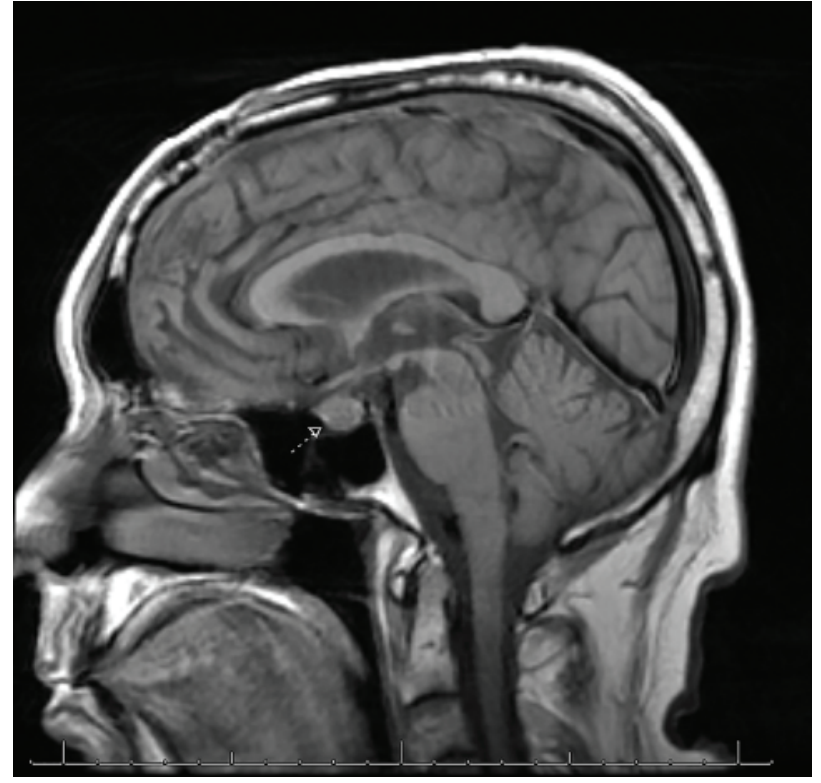

Figure 1. Postcontrast T1-weighted magnetic resonance image of the brain two days prior to the fourth dose of ipilimumab and hospital admission, demonstrating diffuse enlargement of the pituitary gland (arrow).

\section{INTRODUCTION}

Ipilimumab (Yervoy ${ }^{\circledR}$ ) is a human monoclonal antibody that has been shown to significantly improve survival in cases of metastatic melanoma. ${ }^{1}$ I pilimumab blocks cytotoxic T-lymphocyte antigen 4 (CTLA-4), a protein receptor on the surface of $\mathrm{T}$-cells, resulting in their activation, proliferation and an anti-tumor response. ${ }^{2,3,4}$ Commonly reported immune-related side effects of ipilimumab are enterocolitis, dermatitis, and hepatitis. ${ }^{5.6 .7}$ However, different endocrinopathies, including autoimmune hypopituitarism, have become emerging clinical entities in patients taking ipilimumab. We present a case of ipilimumab induced hypophysitis in a 62-yearold male presenting with fatigue and hypotension.

\section{CASE PRESENTATION}

A 62-year-old male with a history of melanoma metastatic to the lung and brain status-post frontal craniotomy and whole brain radiation, as well as a recent diagnosis of hypothyroidism, presented from the oncology office with hypotension after receiving his fourth dose of ipilimumab

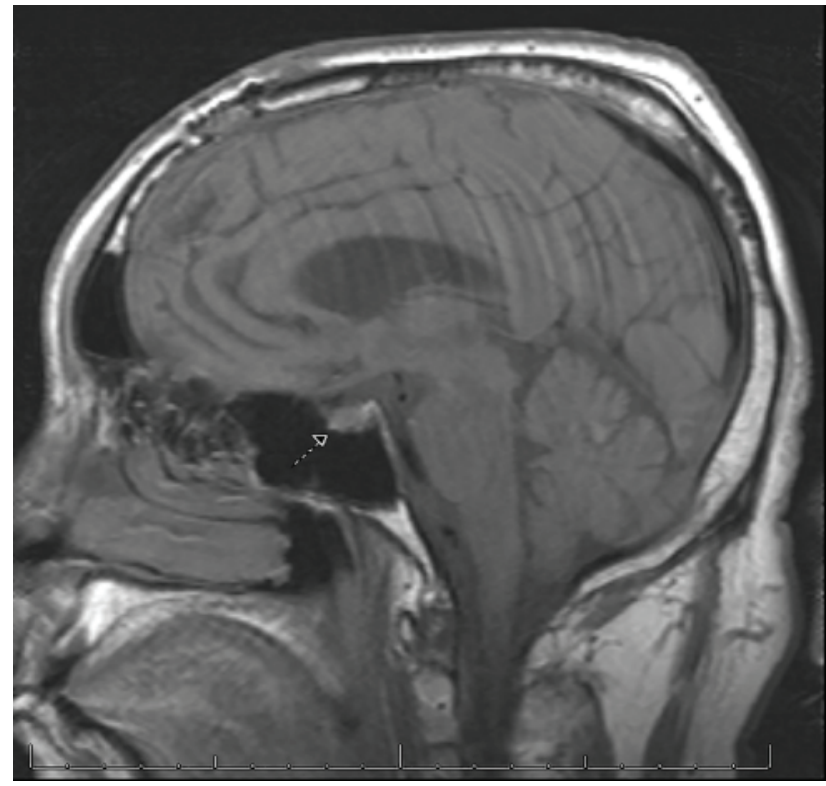

Figure 2. Postcontrast T1-weighted magnetic resonance image of the brain three months before presentation and prior to starting ipilimumab, demonstrating normal pituitary gland architecture and size (arrow).

therapy. The patient had a routine blood pressure check after the chemotherapy infusion and was found to be hypotensive at $80 / 58 \mathrm{mmHg}$. He reported increasing fatigue over the past week. He denied chest pain, shortness of breath, dizziness and headache. He was given one liter of normal saline solution, but remained hypotensive and was directly admitted to the hospital.

On physical exam, the patient was tachycardic to 102 beats per minute with a regular rhythm, clear lungs, and positive orthostatics. Laboratory studies were significant for a thyroid stimulating hormone of $<0.02 \mathrm{ulU} / \mathrm{mL}$ (normal range $=0.3-5 \mathrm{ulU} / \mathrm{mL}$ ), free $\mathrm{T} 4$ of $1.2 \mathrm{ng} / \mathrm{dL}$ (normal range $=0.7-1.7 \mathrm{ng} / \mathrm{dL}$ ), follicle stimulating hormone of $0.9 \mathrm{mlU} / \mathrm{mL}$ (normal range 1.5 - $12.4 \mathrm{mIU} / \mathrm{mL}$ ), adrenocorticotropic hormone (ACTH) of $<9 \mathrm{pg} / \mathrm{mL}$ (normal range $9-46 \mathrm{pg} / \mathrm{mL}$ ), total testosterone of $4 \mathrm{ng} / \mathrm{dL}$ (normal range 250 - $1100 \mathrm{ng} / \mathrm{dL}$, and a free testosterone of $0.4 \mathrm{pg} / \mathrm{mL}$ (normal range $35-155 \mathrm{pg} / \mathrm{mL}$ ). His white blood cell count, hemoglobin and electrolytes were within normal limits. A noon cortisol was $0.3 \mathrm{mcg} / \mathrm{dL}$ (normal A.M. range $16-20 \mathrm{mcg} / \mathrm{dL}$ and P.M. range $2-12 \mathrm{mcg} / \mathrm{dL}$ ) 
and a subsequent cosyntropin stimulation test with $250 \mu \mathrm{g}$ of cosyntropin resulted in cortisol values of $5.4 \mathrm{mcg} / \mathrm{dL}$ and $8.8 \mathrm{mcg} / \mathrm{dL}$ at one hour and two hours respectively. An a magnetic resonance image (MRI) of the brain with and without contrast performed two days earlier for surveillance of his known brain metastases was reviewed on admission and revealed diffuse enlargement of the pituitary gland (Figure 1). This finding was new compared to an MRI performed three months earlier, prior to starting ipilimumab (Figure 2). The patient had no family history of endocrine disorders.

\section{DISCUSSION}

Endocrine-related adverse events were reported in 8.5\% of patients in a recent phase III trial designed to evaluate ipilimumab as an adjuvant therapy following resected stage III melanoma, with hypophysitis encompassing $5.1 \%$ of these events. ${ }^{8}$ The majority of patients who develop hypopituitarism do so after the third or fourth dose of ipilimumab, suggesting a possible cumulative effect. ${ }^{1.3}$ Adverse events have limited the duration of use of the drug in patients who could have clinical benefit from additional therapy.

The mechanism of hypopituitarism is likely from ipilimumab's immunomodulatory effect on activating T-cells, resulting in a lymphocytic hypophysitis. $23,5,6 \mathrm{It}$ has also been shown that some pituitary cells express CTLA-4, the receptor target of ipilimumab. ${ }^{9}$ Therefore, it remains unclear whether the adverse effects are caused by T-cells acting against antigens shared by tumor cells and normal cells or from a direct antibody effect on CTLA-4 receptors on pituitary cells, or both. Presenting symptoms are related to a pituitary mass effect and consequent hormone deficiencies. 5,7.10 Clinical manifestations may be non-specific as they depend on the extent of hormone deficiencies. Additionally, it is often difficult to recognize many of these symptoms in patients undergoing chemotherapy, but there should be a low threshold to consider hypophysitis in a patient taking ipilimumab. Typical symptoms include fatigue, headache, and loss of libido. ${ }^{10}$ Other symptoms could include cold intolerance, visual disturbances, hypotension, hypoglycemia and hyponatremia. Our patient reported fatigue, but his diagnosis only became apparent after hypotension was noted.
MRI findings in ipilimumab-induced hypophysitis are non-specific and are typically characterized by a diffuse enlargement and homogeneous enhancement of the pituitary gland. Less commonly, heterogeneous enhancement has also been described. ${ }^{10-11}$ While it is common to have radiographic evidence of hypopituitarism, a normal MRI is possible. Follow-up imaging often shows resolution of abnormal findings after hormone replacement.11

Pituitary hormone replacement with corticosteroids is critical to treatment, assuming ACTH is low. Either high dose or physiologic replacement dose corticosteroids are needed. Current recommendations advocate for high dose (1-2 mg/kg/day of prednisone or equivalent) steroids for moderate to life threatening symptoms. ${ }^{12}$ However, it is not clear whether initial high doses of corticosteroids are beneficial in treating hypophysitis. While they may play a role in reducing inflammation, they do not improve neuro-endocrine function compared to physiologic doses. However, high doses of corticosteroids may increase morbidity through side effects. ${ }^{3,13}$ Mineralocorticoid replacement is not needed since the renin-angtiotensin-aldosterone system is still intact. It should be at the discretion of the oncologist and endocrinologist as to whether ipilimumab should be continued based on the condition of the patient and response to hormone replacement. Hormone deficiencies can improve, although corticotroph function seems to be the least likely to recover. ${ }^{14}$ Many doctors recommend close monitoring for hormone abnormalities in patients receiving ipilimumab, especially after the third infusion.

\section{KEY POINTS}

Hypophysitis is a well recognized side effect of ipilimumab therapy. A high clinical suspicion for hypopituitarism in patients receiving the drug is imperative due to the non-specific symptoms and potentially life threatening consequences. Corticosteroids should be promptly initiated as soon as secondary adrenal insufficiency is detected. While ipilimumab has many side effects, the drug has improved survival in metastatic melanoma and remains an important treatment option. 


\section{REFERENCES}

1. Hodi FS, O'Day SJ, McDermott DF, Weber RW, Sosman JA, Haanen $J B$, et al. Improved survival with ipilimumab in patients with metastatic melanoma. N Engl J Med 2010; 363(8): 711-23.

2. O'Day SJ, Hamid O, Urba WJ. Targeting cytotoxic T-lymphocyte antigen-4 (CTLA-4): a novel strategy for the treatment of melanoma and other malignancies. Cancer 2007; 110(12): 2614-27.

3. Juszczak A, Gupta, A, Karavitaki N, Middleton MR, Grossman AB. Ipilimumab: a novel immunomodulating therapy causing autoimmune hypophysitis: a case report and review. Eur J Endocrinol 2012; 167(1): 1-5.

4. Fong L, Small EJ. Anti-cytotoxic T-lymphocyte antigen-4 antibody: the first in an emerging class of immunomodulatory antibodies for cancer treatment. J Clin Oncol 2008; 26(32): 5275-83.

5. Weber J. Review: anti-CTLA-4 antibody ipilimubab-case studies of clinical response and immune-related adverse events. Oncologist 2007; 12(7): 864-72.

6. Dillard T, Yedinak CG, Alumkal J, Fleseriu M. Anti-CTLA-4 antibody therapy associated autoimmune hypophysitis: serious immune related adverse events across a spectrum of cancer subtypes. Pituitary 2010; 13(1): 29-38

7. Min L, Vaidya A, Becker C. Association of Ipilimumab therapy for advanced melanoma with secondary adrenal insufficiency: a case series. Endocr Pract 2012; 18(3): 351-55.
8. Eggermont AM, Chiarion-Sileni V, Grob JJ, Dummer R, Wolchok JD, Schmidt $H$, et al. Ipilimumab versus placebo after complete resection of stage III melanoma: Initial efficacy and safety results from the EORTC 18071 phase III trial. J Clin Oncol 32:5s, 2014 (suppl; abstr LBA9008).

9. Iwama S, De Remigis A, Callahan MK, Slovin SF, Wolchok JD, Caturegli P. Pituitary Expression of CTLA-4 Mediates Hypophysitis Secondary to Administration of CTLA-4 Blocking Antibody. Sci Transl Med 2014; 6(230): 230ra45.

10. Chodakiewitz Y, Brown S, Boxerman JL, Brody JM, Rogg JM Ipilimumab treatment associated pituitary hypophysitis: Clinical presentation and imaging diagnosis. Clinical Neurology and Neurosurgery 2014; 125: 125-30.

11. Carpenter KJ, Murtagh RD, Lilienfeld $H$, Weber J, Murtagh FR. Ipilimumab-induced hypophysitis: MR imaging findings. American Journal of Neuroradiology. 2009; 30(9): 1751-53.

12. Yervoy (ipilimumab): Immune-mediated adverse reaction management guide. [Accessed Dec 2014]. Available from http://www.yervoy.com/hcp/pdf/rems-management-guide.pdf.

13. Lammert A, Schneider HJ, Bergmann T, Benck U, Krämer BK, Gärtner R, et al. Hypophysitis caused by ipilimumab in cancer patients: hormone replacement or immunosuppressive therapy. Exp Clin Endocrinol Diabetes. 2013; 121(10): 581-87.

14. Albarel F, Gaudy C, Castinetti F, Carré T, Morange I, Conte-Devolx B, et al. Long-term follow-up of ipilimumab-induced hypophysitis, a common adverse event of the anti-CTLA-4 antibody in melanoma. Eur J Endocrinol. First published online 21 November 2014.

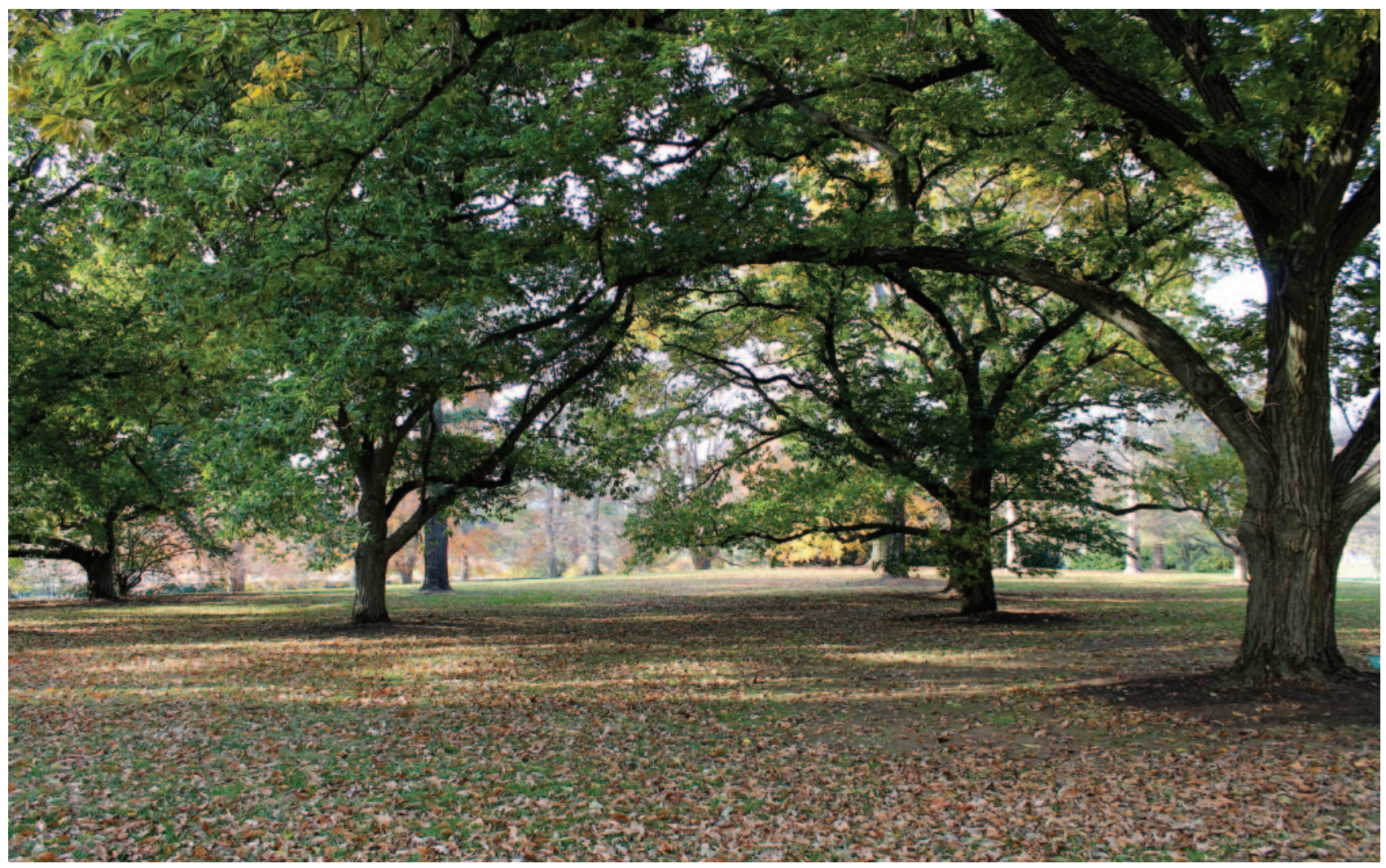

